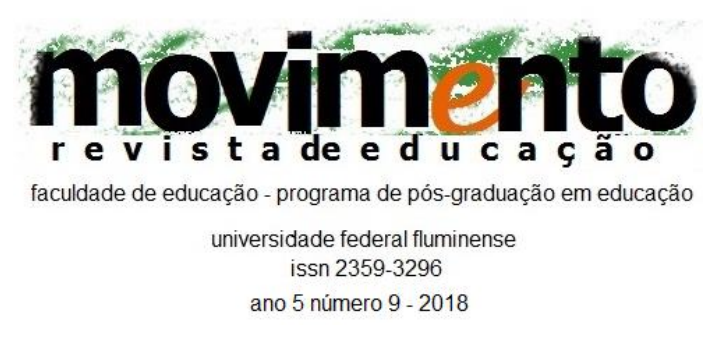

\title{
POLÍTICAS PÚBLICAS DE ACESSO E PERMANÊNCIA NO ENSINO SUPERIOR PÚBLICO BRASILEIRO: O casO da UFRJ
}

\author{
Amanda Gonçalves da Silva \\ Universidade Federal Fluminense, \\ Niterói, RJ, Brasil \\ Joyce Soares Pessanha \\ Universidade Federal Fluminense, \\ Niterói, RJ, Brasil \\ Mariane Brito da Costa \\ Universidade Federal Fluminense, \\ Niterói, RJ, Brasil
}

\begin{abstract}
Resumo
$\mathrm{O}$ artigo tem como objetivo analisar o impacto das recentes políticas de acesso e de permanência na Universidade Federal do Rio de Janeiro (UFRJ). A pesquisa é um estudo de caso e foi desenvolvida por meio da análise de dados do ensino superior brasileiro através do Censo do Ensino Superior e do Sistema de Acesso à Informação do Governo Federal. Os resultados mostram que, apesar de a UFRJ e do governo federal terem conseguido romper algumas barreiras elitistas com a promoção de políticas educacionais, o momento atual demonstra fragilidade na continuidade desses investimentos.

Palavras-chave: Ensino superior; Acesso; Permanência.
\end{abstract}

\section{PUBLIC POLICIES ON ACCESS AND PERMANENCE IN UPPER BRAZILIAN PUBLIC EDUCATION: the case of UFRJ}

\begin{abstract}
The article aims to analyze the impact of recent access and permanence policies at the Federal University of Rio de Janeiro. The research is a case study and was developed through the analysis of Brazilian higher education data through the Census of Higher Education and the Federal Government Information Access System. The results show that although UFRJ and the federal government have managed to break some elitist barriers with the promotion of educational policies, the current moment shows weakness in the continuity of these investments.

Keywords: Higher education; Access; Permanence.
\end{abstract}




\title{
movimento \\ faculdade de educação - programa de pós-graduação em educação \\ universidade federal fluminense \\ issn 2359-3296 \\ ano 5 número 9 - 2018
}

\section{POLÍTICAS PÚBLICAS DE ACCESO Y PERMANENCIA EN LA ENSEÑANZA SUPERIOR PÚBLICA BRASILEÑO: el caso de la UFRJ}

\begin{abstract}
Resumen
El artículo tiene como objetivo analizar el impacto de las recientes políticas de acceso y permanencia en la Universidad Federal de Río de Janeiro. La investigación es un estudio de caso y fue desarrollada por medio del análisis de datos de la enseñanza superior brasileña del Censo de la Enseñanza Superior y del Sistema de Acceso a la Información del Gobierno Federal. Los resultados demuestran que la UFRJ y el gobierno federal lograron romper algunas barreras elitistas con la promoción de políticas educativas, sino el momento actual demuestra fragilidad en la continuidad de esas inversiones.

Palabras clave: Enseñanza superior; Acceso; Permanencia.
\end{abstract}

\section{Introdução}

O artigo tem como objetivo analisar o impacto das políticas de acesso e de permanência promulgadas nas últimas duas décadas e voltadas para os estudantes das camadas populares da Universidade Federal do Rio de Janeiro. A escolha da instituição para análise se justifica por sua imponência como uma das maiores universidades do Brasil e pelo seu processo de criação a partir do agrupamento de faculdades e de cursos superiores voltados para as elites do país. Desse modo, em quase 100 anos de sua criação, quais foram as políticas institucionais e federais criadas para equalizar o acesso e a permanência na instituição? Quais mudanças ocorreram no perfil dos estudantes com a implementação de tais políticas? Um dos problemas de investigação se encontra relacionado à busca por compreender os avanços e os retrocessos das políticas públicas na instituição investigada.

Nas últimas décadas, a expansão do ensino superior brasileiro se intensificou e ocupa um lugar de destaque no cenário nacional, principalmente se considerarmos o impacto dessas políticas no que tange o acesso e a permanência na universidade, em especial, para os estudantes das camadas 


\section{movimento \\ faculdade de educação - programa de pós-graduação em educação \\ universidade federal fluminense \\ issn 2359-3296 \\ ano 5 número 9 - 2018}

populares que até então pouco não se faziam tão presente nos bancos universitários.

Apesar do acesso ao ensino superior no Brasil ter sido ampliado, ainda estamos longe da sua universalização. De acordo com as informações do Observatório do Plano Nacional de Educação, a meta 12 do documento estipula que a taxa bruta ${ }^{1}$ das matrículas na Educação Superior seja elevada até 2024 para 50\% no mínimo. No entanto os dados revelam que

a partir de 2004 houve um crescimento continuado na taxa bruta de matrículas na Educação Superior. De 2009 a 2015 houve um aumento de 6,5 pontos percentuais, atingindo $34,6 \%$ de matrículas na Educação Superior, o que pode ser considerado um ritmo insuficiente para o cumprimento da meta em 2024. (PNE, 2015).

No que se refere à taxa líquida ${ }^{2}$ de matrículas, $18,01 \%$ da população brasileira com faixa etária entre 18 e 24 anos estão matriculados na educação superior (PNE, 2015).

Esses dados nos mostram que, embora o acesso ao ensino superior no Brasil tenha sido ampliado nas últimas décadas, ainda estamos distantes da sua universalização.

Para exemplificar as questões propostas, os dados e as análises aqui apresentados estão ancorados na metodologia do estudo de caso. A pesquisa foi realizada através do aprofundamento e do exame de documentos legais da Educação Superior, como o Censo da Educação Superior e os dados obtidos pelo Sistema de Acesso à Informação do governo federal.

\footnotetext{
${ }^{1}$ Percentual da população na Educação Superior sobre o universo da população de 18 a 24 anos

${ }_{2}^{2}$ Percentual de estudantes de 18 a 24 anos, matriculados em instituições de ensino superior, comparado com a proporção que essa faixa representa na população total.
} 


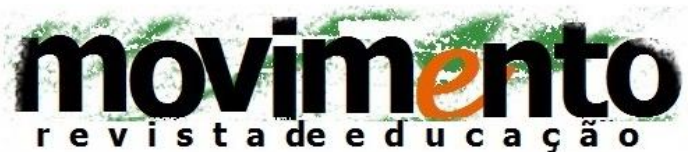 \\ faculdade de educação - programa de pós-graduação em educação \\ universidade federal fluminense \\ issn 2359-3296 \\ ano 5 número 9 - 2018}

Com o intuito de elucidar as questões propostas, apresentaremos um breve panorama do ensino superior público federal brasileiro e da Universidade Federal do Rio de Janeiro, bem como uma análise das informações referentes às políticas de expansão, de acesso e de permanência instituídas na UFRJ.

\section{O ensino superior público federal brasileiro nas últimas duas décadas}

A expansão do ensino superior brasileiro se intensificou nas últimas décadas. No entanto, o seu crescimento ocorreu de forma acentuada no setor privado através de políticas educacionais de caráter mercantilista. A Reforma Universitária de 1968 (Lei n. 5.540/68) e a aprovação da nova Lei de Diretrizes e Bases da Educação Nacional em 1996 colaboraram para que o crescimento do ensino superior se desse, predominantemente, no setor privado. Dessa forma, sua a expansão assumiu um caráter desigual que inviabilizava o acesso equitativo das classes populares.

Mais especificamente a partir dos anos de 1980, houve um intenso aumento do número de matrículas no ensino superior, ganhando ainda mais força a partir da década de 1990. Tal expansão continuou ocorrendo por meio de instituições privadas, sem qualquer relação com o crescimento do ensino público. Com a flexibilização da oferta de ensino por essas universidades, surgem os cursos sequenciais, tecnológicos e a distância como alternativas para o bacharelado convencional de quatro anos.

Nesse contexto, as instituições privadas passaram a oferecer cursos de baixo custo, de modo a atender a demanda de estudantes provenientes das classes média e baixa que encontraram nessas instituições uma possibilidade de ingressar no ensino superior. Entretanto, é possível observar que a ampliação 


\section{movimento \\ faculdade de educação - programa de pós-graduação em educação \\ universidade federal fluminense \\ issn 2359-3296 \\ ano 5 número 9 - 2018}

da oferta de cursos não ocorreu em todas as áreas do conhecimento. $O$ crescimento do setor privado predominou em

cursos de baixos custos voltados às humanidades, ao direito e à administração. A oferta de cursos das chamadas "ciências duras", como engenharia, medicina, física, biotecnologia e química, permaneceu, majoritariamente, sob a iniciativa pública (COMIN; BARBOSA, 2011, p. 76).

Nos governos de Fernando Henrique Cardoso (1995-2003), as políticas educacionais mercantilistas se intensificaram e a educação assumiu um papel econômico embasado nos princípios neoliberais com acentuada participação do empresariado, atendendo aos interesses dos organismos internacionais como o Fundo Monetário Internacional (FMI) e o Banco Mundial (BM).

A criação do Programa de Financiamento Estudantil (FIES), destinado ao financiamento de cursos de graduação em instituições privadas de ensino superior, na forma da Lei 10.260/2001, retrata o traço mercantil que a educação passou a assumir.

De acordo com os dados fornecidos pelo Instituto Nacional de Pesquisas Anísio Teixeira (INEP, 2002), no início do governo de Fernando Henrique Cardoso (FHC), o Brasil possuía 684 instituições privadas. Já em 2002, 0 número cresce para 1442, o que caracteriza um aumento de 110\% em 7 anos.

No que concerne às instituições públicas, a expansão ocorreu com o aumento de vagas, mas com parcos investimentos em novas instituições e sem a promoção de melhorias naquelas já existentes. Em 1995, primeiro ano do governo FHC, o ensino superior público contava com 210 instituições, 2782 cursos e 700.540 matrículas. Já em 2002, eram 195 instituições, 5252 cursos e 1.051 .655 matrículas. 


\section{$\underset{r e v i s t a d e d u c t o c s}{\operatorname{movim}}$ \\ faculdade de educação - programa de pós-graduação em educação \\ universidade federal fluminense \\ issn 2359-3296 \\ ano 5 número 9 - 2018}

Nesse mesmo período, não foram desenvolvidas políticas públicas direcionadas para o acesso e para a permanência no ensino superior público. O Exame Nacional do Ensino Médio (ENEM) foi instituído pelo Ministério da Educação (MEC) como um indicador do nível intelectual dos alunos para ser valorizado pelas empresas e como substituto do vestibular para ingresso nas universidades. Porém, o exame não foi instituído como uma política e não era obrigatória a adesão das instituições de ensino durante o governo FHC.

Nos governos de Luiz Inácio Lula da Silva (2003-2011), alguns ideários da doutrina neoliberal foram mantidos, dando continuidade aos incentivos à expansão do ensino superior pela via privada. De acordo com dados do Inep, no primeiro ano do governo Lula, o Brasil possuía 1652 instituições privadas. Ao final desse mesmo governo, essas instituições totalizavam 2081. Como reflexo desses incentivos, o governo criou o Programa Universidade para Todos (ProUni) em 2005, o qual destina bolsas de 50\% e 100\% em instituições de ensino superior privadas para estudantes egressos do ensino médio e que tenham realizado o Exame Nacional do Ensino Médio (ENEM).

No que se refere ao setor público, foram implementadas políticas direcionadas para o acesso, a expansão e a permanência no ensino superior. Foi durante os governos Lula que o Exame Nacional do Ensino Médio (Enem) foi reformulado. Simultaneamente, com a criação da plataforma do Sistema de Seleção Unificada (Sisu), ambos - Sisu e Enem -tornaram-se mecanismos de acesso às universidades federais. Agora os estudantes de diferentes regiões do país podem ingressar em instituições distantes de seus locais de moradia.

A inserção no ensino superior público federal dos estudantes afastados dos centros metropolitanos tornou-se possível em algumas regiões do país através Programa de Apoio a Planos de Reestruturação e Expansão das Universidades 


\section{movimento \\ faculdade de educação - programa de pós-graduação em educação \\ universidade federal fluminense \\ issn 2359-3296 \\ ano 5 número 9 - 2018}

Federias (Reuni). Esse projeto foi implementado com o propósito de ampliar o acesso e a permanência na educação superior, através do melhor aproveitamento da estrutura física e dos recursos humanos existentes nas instituições federais.

As iniciativas objetivando a permanência e a conclusão dos estudantes no ensino superior, especialmente aqueles provenientes das classes populares, podem ser observadas através da implementação do Programa Nacional de Assistência Estudantil (PNAES) para estudantes matriculados em cursos presenciais de universidades federais e o Programa Nacional de Assistência Estudantil para as instituições de educação superior públicas estaduais (PNAEST) que utilizaram o Enem como processo de seleção.

Dando continuidade às políticas implementadas nos governos anteriores, a presidenta Dilma Rouseff ${ }^{3}$ (2011-2016) manteve os investimentos na expansão das instituições privadas de ensino superior com a manutenção do FIES (Fundo de Financiamento Estudantil) e do Prouni (Programa Universidade para Todos). Este último é regulamentado pela Lei oㅜ 11.096 de 13 de janeiro de 2005, a qual possibilita aos estudantes ingressarem no ensino superior privado com bolsa parcial ou integral concedida pelo governo federal.

No ensino superior público, um dos maiores avanços no governo da presidenta foi a promulgação da Lei 12.711 (Lei de Cotas) de 29 de agosto de 2012. Ela prevê reserva de $50 \%$ das vagas de instituições federais de ensino superior para estudantes egressos de instituições públicas de ensino médio que combinem critérios cor/etnia (pretos, pardos e indígenas) com sociais (renda familiar de até 1,5 salários mínimos). Assim,

\footnotetext{
${ }^{3}$ A presidenta teve seu mandato interrompido em 31 de agosto de 2016.
} 


\section{movimento \\ faculdade de educação - programa de pós-graduação em educação \\ universidade federal fluminense \\ issn 2359-3296 \\ ano 5 número 9 - 2018}

A aprovação da Lei de Cotas afirma a ideia democrática de que a educação superior é para todos e não somente para grupos privilegiados. Apesar dos avanços nos últimos anos, o campus brasileiro continua sendo um espelho que distorce a sociedade. Números analisados e contas feitas, a conclusão a que se chega é uma só: os cursos de graduação hipertrofiam, no campus, as desigualdades existentes (RISTOFF, 2011, p.24).

A adesão ao Sisu, pelos institutos e pelas universidades federais, trouxe a possibilidade de democratização do acesso às vagas em instituições de ensino público e promoveu a mobilidade acadêmica dos estudantes dos mais variados locais do Brasil. Ou seja,

Com a implementação do Sisu, tornou-se mais acessível a consulta a candidatura por vagas de instituições de diversas partes do país. Com a possibilidade de se consultar a nota de corte parcial dos cursos ofertados, potencialmente há maiores chances de se ter sucesso no pareamento entre alunos e vagas. Um resultado esperado é um aumento dos pareamentos entre alunos e vagas de locais distintos, ou seja, um aumento da migração dos alunos em busca de uma vaga no ensino superior (LI, 2016, p.31).

Durante o governo Dilma, também foi criado o Programa Ciência sem Fronteiras ${ }^{4}$ (CsF) de estágio em instituições estrangeiras para estudantes da graduação e da pós-graduação.

Com a implementação dessas novas políticas e com a continuidade daquelas já promulgadas durante o governo Lula, houve um crescimento no número de matrículas nas instituições de ensino superior. De acordo com as informações do Censo da Educação Superior de 2014, ao serem comparados o número de

\footnotetext{
${ }^{4} \mathrm{O}$ Ciência sem Fronteiras é um dos programas desenvolvidos em parceria com o Ministério da Ciência, Tecnologia e Inovação (MCTI) e com o Ministério da Educação (MEC) - por meio de suas respectivas instituições de fomento (CNPq e Capes) - e Secretarias de Ensino Superior e de Ensino Tecnológico do MEC. Ele era destinado a oferecer intercâmbio e mobilidade internacional aos estudantes de graduação e pós-graduação através de estágio no exterior. No ano de 2016, o governo encerrou esse programa na modalidade de cursos para graduação, passando a atender apenas os cursos de pós-graduação, como mestrado, doutorado e pós-doutorado.
} 


\section{movimento \\ faculdade de educação - programa de pós-graduação em educação \\ universidade federal fluminense \\ issn 2359-3296 \\ ano 5 número 9 - 2018}

matrículas do último ano do governo Lula e o do ano de 2014, encontra-se um crescimento de $15,7 \%$ delas em três anos (INEP, 2014).

\section{O caso UFRJ: contexto histórico e institucional}

O período que antecedeu o surgimento das primeiras instituições de ensino superior no Brasil foi demarcado por tentativas e resistências. Tais conflitos ocorreram, inicialmente, entre a Metrópole e a Colônia e, posteriormente, ao longo da Monarquia e da Primeira República. À época, foram criados cursos de formação superior nas áreas de filosofia, teologia, medicina, direito e engenharia. Somente em 1920 foi criada a primeira universidade brasileira: Universidade do Rio de Janeiro (URJ) (Fávero, 2006). Reorganizada em 1937, passou a se chamar Universidade do Brasil e, em 1965, Universidade Federal do Rio de Janeiro.

Atualmente, a UFRJ possui 139 cursos com habilitação em licenciatura e bacharelado e ofertados nos seguintes campi: Rio de Janeiro, Macaé e Xerém. A instituição também integra o Centro de Educação Superior a Distância do Estado do Rio de Janeiro (Cederj), com 12 polos de ensino nessa modalidade (UFRJ, 2013). Como produto do plano de Reestruturação e Expansão das universidades federais (Reuni), ocorreu a ampliação dessa instituição para os os campi de Xerém e de Macaé, de forma a contribuir para a interiorização do ensino superior em distintas regiões do Rio de Janeiro.

Cabe ressaltar que o processo de expansão e de interiorização dessa instituição aconteceu durante o mandato do presidente Luiz Inácio Lula da Silva, ancorado nas propostas do Plano Nacional de Educação (PNE) de 2001, o qual previa uma política de expansão do ensino superior com a finalidade de minimizar as desigualdades entre as diferentes regiões do país. Essa política, 


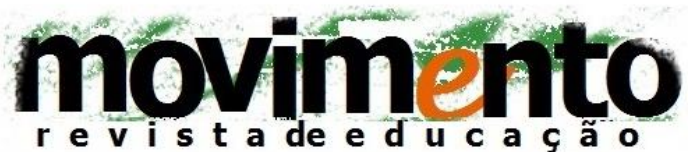 \\ faculdade de educação - programa de pós-graduação em educação \\ universidade federal fluminense \\ issn 2359-3296 \\ ano 5 número 9 - 2018}

no âmbito do ensino superior, assumiu um papel importante, pois tinha como foco principal a intenção de contribuir para a redução das desigualdades sociais que se manifestam nas dificuldades de acesso e de permanência vividas pelos estudantes que moram distante dos centros urbanos ou em regiões periféricas.

O PNE (2001) previa, dentre outros objetivos gerais ${ }^{5}$ : prover, até o final da década, a oferta de educação superior para, pelo menos, 30\% da faixa etária de 18 a 24 anos; estabelecer uma política de expansão que diminuísse as desigualdades de oferta existentes entre as diferentes regiões do país; criar políticas que facilitassem às minorias, vítimas de discriminação, o acesso à educação superior, através de programas de compensação de deficiências de sua formação escolar anterior, permitindo-lhes, dessa forma, competir em igualdade de condições nos processos de seleção e de admissão a esse nível de ensino; implantar o Programa de Desenvolvimento da Extensão Universitária em todas as Instituições Federais de Ensino Superior no quadriênio 2001-2004 e assegurar que, no mínimo, 10\% do total de créditos exigidos para a graduação no ensino superior no país estivessem reservados para a atuação dos alunos em ações extensionistas.

Diante das políticas de expansão do ensino superior, da necessidade de ampliação do número de vagas e da incorporação de mecanismos democráticos de ingresso, a UFRJ reflete sobre a construção de alternativas ao processo seletivo do vestibular que fossem menos seletivos e restritivos, e, desde então, constrói um novo olhar sobre as medidas afirmativas de acesso aos cursos superiores.

\footnotetext{
${ }^{5}$ Disponível em: http://www.planalto.gov.br/ccivil 03/leis/leis 2001/l10172.htm. Acesso em: 22 fev. 2018.
} 


\section{movimento \\ faculdade de educação - programa de pós-graduação em educação \\ universidade federal fluminense \\ issn 2359-3296 \\ ano 5 número 9 - 2018}

A partir desse contexto, entendemos a importância de uma análise mais criteriosa sobre os reflexos das diferentes ações promovidas pela UFRJ, percebendo os avanços e os retrocesso das políticas públicas no ensino superior.

\section{Os desafios da educação superior: as políticas de expansão, de acesso e de permanência na UFRJ}

As mudanças ocorridas durante os governos Lula e Dilma significaram um grande avanço na promoção de políticas públicas voltadas para o acesso e para a permanência de estudantes das camadas populares no ensino superior. Com a promulgação da Lei oㅜ 12.711/2012, a UFRJ passou a realizar a reserva de vagas como forma de lei em seu processo de acesso para o ano de 2013 (UFRJ, 2012). Inicialmente, a instituição adotou, em cada curso/opção, 30\% das vagas por ação afirmativa para estudantes egressos de instituições públicas de ensino médio. Essas vagas foram distribuídas da seguinte forma:

I. $50 \%$ das vagas de que trata o caput deste artigo serão destinadas a candidatos com renda familiar bruta per capita igual ou inferior a um salário mínimo e meio vigente.

II. $51,8 \%$ das vagas de cada um dos grupos resultantes após a aplicação do percentual definido no inciso I, correspondente a soma de pretos, pardos e indígenas na população do Estado do Rio de Janeiro conforme o censo demográfico de 2010 divulgado pelo Instituto Brasileiro de Geografia e Estatística - IBGE, serão destinadas por curso/opção, aos autodeclarados pretos, pardos e indígenas. (UFRJ, 2012).

De acordo com a Lei 12.711/2012, as instituições possuem o período de quatro anos para atingirem a meta proposta.

Art. 8॰ As instituições de que trata o art. 10 desta Lei deverão implementar, no mínimo, $25 \%$ (vinte e cinco por cento) da reserva de vagas prevista nesta Lei, a cada ano, e terão o prazo máximo de 4 (quatro) anos, a partir da data de sua publicação, para o cumprimento integral do disposto nesta Lei (BRASIL, 2012). 


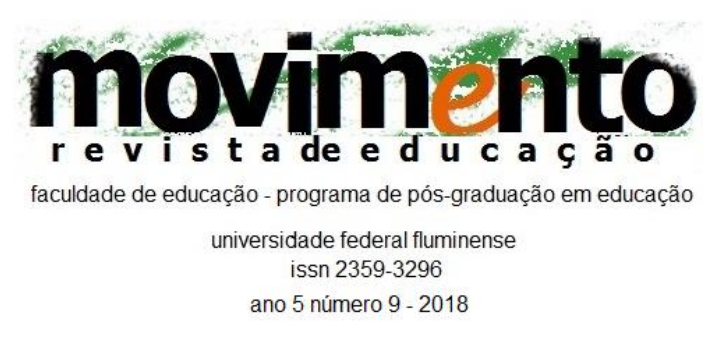

Já no processo de acesso do ano subsequente, a UFRJ dispôs da reserva de $50 \%$ das vagas para estudantes dentro dos critérios da lei, com a mesma distribuição de vagas citada anteriormente e que se mantem até os dias atuais.

No que concerne ao processo de seleção na universidade, ele é realizado pelo Sistema de Seleção Unificada (Sisu). Esse programa foi desenvolvido pelo Ministério da Educação (MEC) para selecionar os candidatos às vagas das instituições públicas de ensino superior e utiliza a nota do Exame Nacional do Ensino Médio (ENEM) como base.

Anteriormente à promulgação da política de reserva de vagas e de mudança no acesso através do SiSU/ENEM, em 2011, a UFRJ começou a utilizar um sistema próprio de reserva de vagas, no qual destinava $20 \%$ das vagas para estudantes que cursaram integralmente o ensino médico na rede pública do Rio de Janeiro e que utilizaram o ENEM/SiSU para seleção. As demais vagas foram distribuídas da seguinte forma: $40 \%$ do acesso através do vestibular e $40 \%$ por meio do ENEM/SiSU. A discussão por uma política afirmativa esteve presente na pauta do Conselho Universitário desde 2004, no entanto, devido à intensa resistência, só em 2010 a reserva própria foi manifestada e implementada no vestibular de 2011.

Nesse mesmo período, em 2011, foram adotados novos critérios para ingresso no ano subsequente:

a UFRJ abriu mão do processo seletivo próprio e passou a adotar somente o ENEM como avaliação e o SISU como sistema de acessos a uma vaga nos cursos de graduação, respeitando o Teste de Habilidade Específica para alguns deles" (HERINGER; HONORATO, 2014, p. 334). 


\section{movimento \\ faculdade de educação - programa de pós-graduação em educação \\ universidade federal fluminense \\ issn 2359-3296 \\ ano 5 número 9 - 2018}

Posteriormente, em 2012, o Conselho Universitário da UFRJ reafirmou a proposta de utilizar o ENEM, o SISU e o Teste de Habilidade Específica como processo para ingresso na instituição. Entretanto,

destinando $30 \%$ das vagas oferecidas em cada curso a candidatos que tivessem cursado integralmente o ensino médio em escolas das rede pública e que apresentassem renda familiar per capita de até um salário mínimo nacional vigente" (HERINGER; HONORATO, 2014, p. 334).

Os dados a seguir, referentes aos ingressantes por política de reserva de vagas na UFRJ, no período de 2011 a 2017, mostram que aproximadamente $16 \%$ de um total de 11.825 estudantes eram beneficiários da reserva institucional em 2011. Nesse mesmo ano, a UFRJ possuía um sistema próprio de reserva de vagas. Já em 2013, ano posterior à implementação da "Lei de Cotas", dos 11.386 estudantes, cerca de $29 \%$ ingressaram através da ação afirmativa. Os dados de 2017 sinalizam que por volta de $40 \%$ dos ingressantes são cotistas de um montante de 11.688 estudantes.

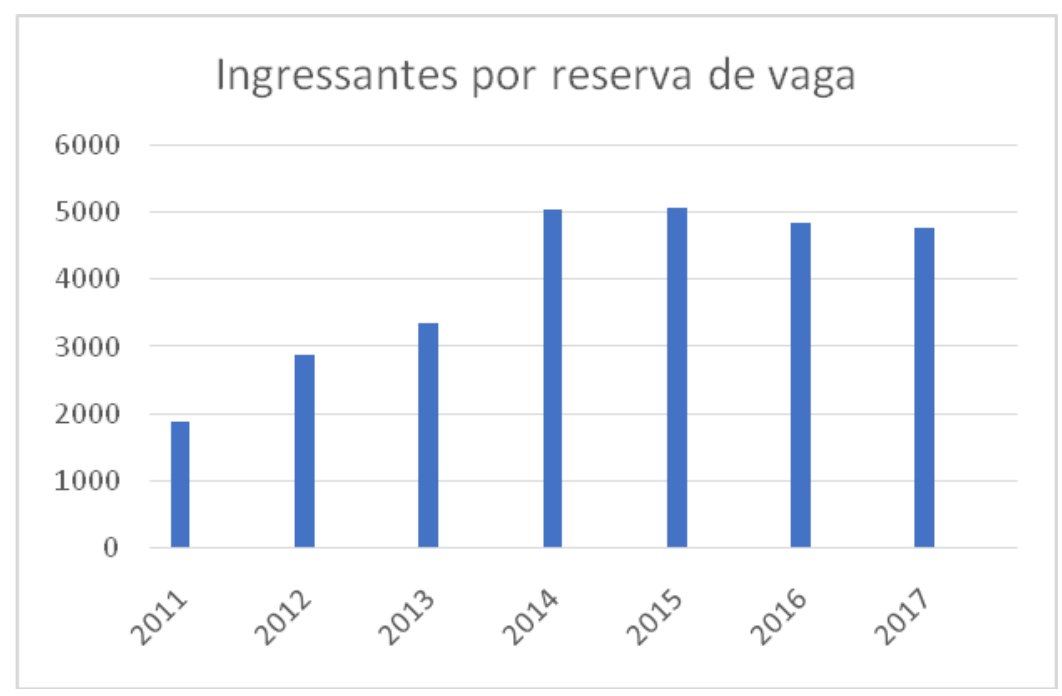

Gráfico 1: Ingressantes por reserva de vagas (2011 - 2017). Fonte: Sistema de Acesso a Informação da UFRJ. 


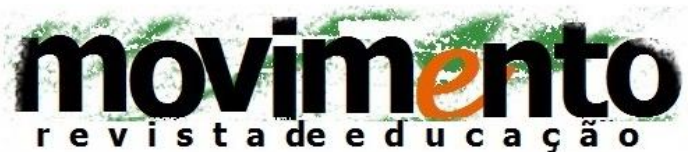 \\ faculdade de educação - programa de pós-graduação em educação \\ universidade federal fluminense \\ issn 2359-3296 \\ ano 5 número 9 - 2018}

Esses resultados nos revelam um aumento do acesso à universidade por meio de políticas afirmativas instituídas pela própria instituição de ensino. Tal fato representa um significativo avanço no que se refere ao acesso ao ensino superior nas últimas décadas, uma vez que esse nível de ensino, historicamente, foi destinado à formação das elites.

Diante de um ensino superior criado e direcionado às elites brasileiras, as discussões sobre a continuidade dos estudantes das camadas populares nas universidades se fizeram presentes. Antes mesmo de o governo federal realizar investimentos em políticas de assistência e de permanência estudantis, a UFRJ já discutia tais medidas. De acordo com Magalhães (2013), desde a década de 70, a instituição tem programas de assistência estudantil desenvolvidos e coordenados pela Divisão de Assistência ao Estudante (DAE). Entretanto, até a década de 90, a DAE não desenvolveu "estudos, pesquisas ou produções teóricas significativas sobre o tema da assistência estudantil que pudesse dar subsídios necessários a implementação de uma política institucional de assistência estudantil" (p. 74).

Foi apenas em 1990 que a então diretora da DAE, Profa. Maria Durvalina Fernandes Bastos, desenvolveu o documento "Projetos da Divisão de Assistência Estudantil ao Estudante - DAE". Tal projeto

buscava o desenvolvimento de programas e ações de assistência estudantil articulados à formação acadêmica do estudante a ser desenvolvida nos 4 anos seguintes e apresenta uma concepção de assistência estudantil como parte integrante da formação global do estudante. (MAGALHÃES, 2013, p. 75).

De acordo com as informações da instituição, somente em 1996 é possível identificarmos (um número irrisório) estudantes beneficiados com a bolsa de assistência estudantil. A partir de 2002, houve uma expansão no número de discentes assistidos pela bolsa. 


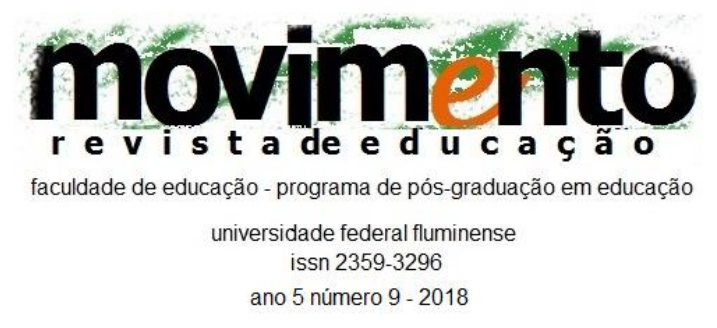

\begin{tabular}{|c|c|c|c|c|c|}
\hline Ano & Semestre & $\begin{array}{c}\text { Assistência } \\
\text { estudantil }\end{array}$ & Ano & Semestre & $\begin{array}{l}\text { Assistência } \\
\text { estudantil }\end{array}$ \\
\hline \multirow{2}{*}{1996} & 1996.1 & 1 & \multirow{2}{*}{2007} & 2007.1 & 225 \\
\hline & 1996.2 & 1 & & 2007.2 & 193 \\
\hline \multirow{2}{*}{1997} & 1997.1 & 1 & \multirow{2}{*}{2008} & 2008.1 & 215 \\
\hline & 1997.2 & 1 & & 2008.2 & 262 \\
\hline \multirow{2}{*}{1998} & 1998.1 & 1 & \multirow{2}{*}{2009} & 2009.1 & 272 \\
\hline & 1998.2 & 3 & & 2009.2 & 229 \\
\hline \multirow{2}{*}{1999} & 1999.1 & 2 & \multirow{2}{*}{2010} & 2010.1 & 438 \\
\hline & 1999.2 & 6 & & 2010.2 & 425 \\
\hline \multirow{2}{*}{2000} & 2000.1 & 8 & \multirow{2}{*}{2011} & 2011.1 & 865 \\
\hline & 2000.2 & 15 & & 2011.2 & 546 \\
\hline \multirow{2}{*}{2001} & 2001.1 & 9 & \multirow{2}{*}{2012} & 2012.1 & 1736 \\
\hline & 2001.2 & 16 & & 2012.2 & 1030 \\
\hline \multirow{2}{*}{2002} & 2002.1 & 96 & \multirow{2}{*}{2013} & 2013.1 & 979 \\
\hline & 2002.2 & 101 & & 2013.2 & 711 \\
\hline \multirow{2}{*}{2003} & 2003.1 & 130 & \multirow{2}{*}{2014} & 2014.1 & 1168 \\
\hline & 2003.2 & 166 & & 2014.2 & 847 \\
\hline \multirow{2}{*}{2004} & 2004.1 & 217 & \multirow{2}{*}{2015} & 2015.1 & 733 \\
\hline & 2004.2 & 177 & & 2015.2 & 392 \\
\hline \multirow{2}{*}{2005} & 2005.1 & 233 & \multirow{2}{*}{2016} & 2016.1 & 1147 \\
\hline & 2005.2 & 179 & & 2016.2 & 817 \\
\hline \multirow{2}{*}{2006} & 2006.1 & 223 & \multirow{2}{*}{2017} & 2017.1 & 1136 \\
\hline & 2006.2 & 201 & & 2017.2 & 410 \\
\hline & & & & Total & 16563 \\
\hline
\end{tabular}

Tabela 1: Quantidade de estudantes beneficiados com bolsa de assistência estudantil (1996 2017).

O crescimento do número de bolsas estudantis se deu de forma mais intensa a partir do ano de 2012. Elas são ofertadas pela universidade com a finalidade de melhorar as condições de permanência dos estudantes e as oportunidades de acesso a um ensino superior de qualidade. Além disso, com os recursos destinados através do PNAES, a UFRJ desenvolveu ações que visavam a minimizar as dificuldades dos alunos pertencentes às camadas populares. 


\title{
movimento \\ faculdade de educação - programa de pós-graduação em educação \\ universidade federal fluminense issn 2359-3296 \\ ano 5 número 9 - 2018
}

\begin{abstract}
Através da Bolsa Acesso e Permanência e Bolsa Auxílio ao Estudante 6 , discentes que comprovassem renda per capita inferior ou igual a 1,5 salários mínimos teria direito a ela. Essa bolsa é dividida em duas modalidades: benefício moradia e bolsa auxílio.
\end{abstract}

- Bolsa Acesso e Permanência: destinada a todos os estudantes ingressantes por reserva de vagas (ação afirmativa). A bolsa possui vigência apenas no ano de ingresso. Após esse período, é necessário que o beneficiado solicite a Bolsa Auxílio.

Benefício: $R \$ 460,00$ mensais e Auxílio Transporte (de $R \$ 165,00$ a $R \$$ 297,00 dependendo do local de residência)

- Bolsa Auxílio: é destinada para estudantes que comprovem dificuldades de garantir sua permanência na UFRJ em função de recursos econômicos limitados. A bolsa pode ser solicitada por discentes ingressantes por reserva de vaga ou não. Os beneficiários não podem acumular esse benefício com a Bolsa Moradia.

Benefício: $\mathrm{R} \$ 460,00$ mensais e Auxílio Transporte ( $\mathrm{R} \$ 150,00$ mensais).

- Bolsa Moradia: direcionada a estudantes que comprovem dificuldades de permanência em função da distância entre o local de moradia familiar e os campi universitários.

\footnotetext{
${ }^{6}$ Regulamentada pela Resolução CEG 01/2008 - Normas de concessão e renovação de Auxílio ao estudante. (UFRJ, 2008). Para solicitar a Bolsa Auxílio ao Estudante, é necessário que seja obedecido os seguintes critérios: a) estar regularmente matriculado em curso de graduação da UFRJ; b) demonstrar dificuldades socioeconômicas; c) não ter concluído qualquer curso de graduação; d) não ter sofrido sanção disciplinar; e) estar inscrito, no mínimo, em 20 (vinte) horas semanais em disciplinas de graduação da UFRJ ou ter um parecer da Comissão de Orientação e Acompanhamento Acadêmico (COAA) justificando inscrição em carga horária menor; f) não se enquadrar nas situações previstas para o cancelamento de matrícula; g) apresentar CRA > 3,0; h) não apresentar três reprovações ou mais em uma mesma disciplina do curso em que estiver regularmente matriculado. A concessão da bolsa é realizada através da análise socioeconômica do estudante e a distância entre a universidade e local de moradia do aluno e de sua família. Ela tem vigência de 12 meses, renovável anualmente, caso o estudante cumpra os critérios citados anteriormente. (PR-7, 2018).
} 


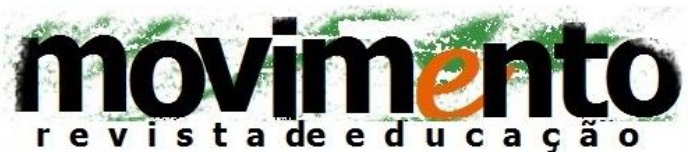 \\ faculdade de educação - programa de pós-graduação em educação \\ universidade federal fluminense \\ issn 2359-3296 \\ ano 5 número 9 - 2018}

Benefício: uma vaga na Residência Estudantil, $R \$ 460,00$ mensais e Auxílio Transporte ( $R \$ 150,00$ mensais).

Observação: uma vez que a Residência Estudantil está em reformas desde 2003, não podendo receber novos selecionados ao Benefício Moradia, a UFRJ disponibiliza a "Bolsa Moradia Emergencial" no valor de $R \$ 1.260,00$ (já incluído o valor de auxílio transporte) até a conclusão das obras da Residência Estudantil, quando será retomado o encaminhamento para a ocupação das vagas e o aluno passará a receber tão somente o Auxílio Moradia no valor de $R \$ 460,00$, acrescido de auxílio transporte, no valor fixo de $\mathrm{R} \$ 150,00$.

Cabe salientarmos as distinções entre as ações de assistência estudantil, que são direcionadas para os estudantes com dificuldades socioeconômicas, e as de permanência. Concordamos com Honorato quando evidencia que

[...] as ações de assistência estudantil teriam um foco mais específico, sendo dirigidas à gestão das dificuldades em custear livros e fotocópias, ao pagamento de refeições para se manter na instituição de ensino pelo menos para estar presente nas aulas, ao custo com deslocamento de casa e/ou trabalho até a universidade e de alojamento/residência estudantil. Há autores que também consideram a atenção a "necessidades especiais", por exemplo, atendimento psicológico e/ou psiquiátrico dos estudantes. [...] O próprio PNAES amplia a definição para "atenção à saúde"; "inclusão digital"; "cultura"; "esporte"; "creche"; "apoio pedagógico"; "acesso, participação e aprendizagem de estudantes com deficiência, transtornos globais do desenvolvimento e altas habilidades e supertodação" (HONORATO, 2015, p. 100).

Para Heringer e Honorato (2015), muito além do acesso através de políticas afirmativas, é necessário pensarmos nas políticas de assistência e de permanência do estudante, pois essas

parecem ser os principais desafios do processo de democratização das oportunidades de acesso ao ensino superior no Brasil. Uma vez admitidos às instituições de ensino, como fazer com que um amplo contingente de alunos 


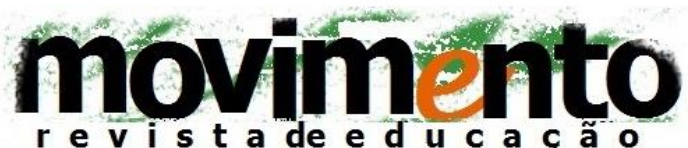 \\ faculdade de educação - programa de pós-graduação em educação \\ universidade federal fluminense \\ issn 2359-3296 \\ ano 5 número 9 - 2018}

tenha condições de permanecer "efetivamente" em seus cursos de graduação? (p.11).

A oferta de bolsas para os estudantes da UFRJ desde o ingresso na universidade torna-se relevante, pois o processo de seleção não acontece apenas no ENEM, mas durante toda a vida escolar. Não podemos negar que há diferenças entre a educação ofertada para as classes mais pobres, que frequentam a escola pública, e aquela oferecida para as mais abastadas que frequentam o ensino privado de elite. Essa distinção constitui mais um obstáculo que pode comprometer ou inviabilizar o prosseguimento dos estudos na universidade. Isso posto, há que se refletir ainda sobre o desafio que "é construir um aparato de apoio aos jovens pobres que vêm adentrando as universidades públicas para além de um atendimento material" (PORTES, 2015, p.140).

Ademais, a UFRJ colocou em prática outras ações e estratégias para minimizar os efeitos das desigualdades sociais e regionais por meio da oferta de programas e de projetos que são regulamentados pela Pró-Reitoria de Políticas Estudantis (PR-7) ${ }^{7}$. Os discentes ingressantes por políticas de ação afirmativa e os bolsistas possuem o apoio da Divisão de Saúde do Estudante que tem como objetivo promover a qualidade de vida do alunado no ambiente acadêmico. Além disso, contam com a Divisão de Inclusão, Acessibilidade e Assuntos Comunitários - repartição que busca integrar e promover ações na área da inclusão, acessibilidade e assuntos comunitários - e com a Divisão de Esportes, Cultura e Lazer - responsável por divulgar atividades que colaboram com o saber, com as relações e com o bem-estar dos estudantes.

\footnotetext{
${ }^{7}$ Durante um longo período, as ações de assistência e permanência foram regulamentas pela Superintendência de Assuntos Estudantis (SUPEREST), após um grande período de reinvindicações partindo dos estudantes e funcionários, a SUPEREST foi reformulada e transformou-se na Pró-Reitoria de Políticas Estudantis (PR-7). Tal fato demonstra um grande avanço para discussões e melhorias das políticas de assistência e permanência desenvolvidas pela instituição.
} 


\section{movimento \\ faculdade de educação - programa de pós-graduação em educação \\ universidade federal fluminense \\ issn 2359-3296 \\ ano 5 número 9 - 2018}

Além das ações citadas, algumas outras são realizadas pela instituição, como a moradia estudantil $^{8}$, o restaurante universitário ${ }^{9}$ e o transporte interno entre os campi da UFRJ. Tais medidas buscam minimizar as dificuldades enfrentadas durante o percurso acadêmico em uma instituição que, ao longo da história, preservou uma postura conservadora no que tange ao acesso de estratos sociais em desvantagem socioeconômica. Entretanto, cabe salientar que tais atuações, como o restaurante universitário e alojamento universitário, não estão disponíveis em todos os campi e polos da universidade, o que inviabiliza uma definição dessa ação como plenamente democrática, pois não atende a todos os estudantes para qual ela é destinada.

\section{Considerações Finais}

As facetas das desigualdades de acesso e de permanência no ensino superior se tornam mais nítidas quando atentamos para as dificuldades causadas pela carência de uma educação escolar de qualidade que possibilite equidade no momento da disputa por uma vaga na universidade. Há que se pensar, ainda, na influência que os fatores econômicos e sociais exercem na escolha do curso universitário, ou seja, para os sujeitos das classes populares, na maioria das vezes, o acesso ao ensino superior está atrelado à escolha do curso. Desse modo, ela se determina em função do prestígio que esse assume na escala social.

\footnotetext{
${ }^{8} \mathrm{O}$ alojamento estudantil está localizado no campus do Fundão e uma parte encontra-se em obra. As reformas iniciaram em 2013 e a previsão de entrega seria de 600 dias (aproximadamente 1 ano e 7 meses). Segundo informações da AdUFRJ, esse prazo - previsto para 14 de setembro de 2016 - não foi atendido (AdUFRJ, 2016a). Em julho de 2017, uma parte da moradia estudantil pegou fogo e deixou inúmeros alunos desabrigados.

O restaurante universitário está disponível apenas no campus do Fundão e possui três unidades. São servidos almoços e jantares de segunda a domingo e as refeições custam $\mathrm{R} \$ 2,00$ para todos os alunos da universidade (valores referentes ao ano de 2018). Em alguns polos e unidades, são distribuídas refeições em forma de lanches e quentinhas, sendo uma prática recente da UFRJ (AdUFRJ, 2016b).
} 


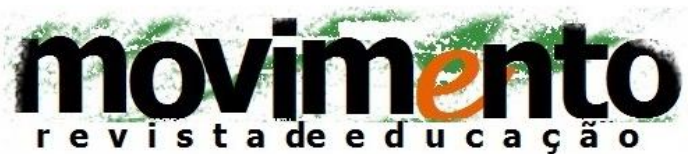 \\ faculdade de educação - programa de pós-graduação em educação \\ universidade federal fluminense \\ issn 2359-3296 \\ ano 5 número 9 - 2018}

Vargas (2008) afirma que, embora as políticas de expansão e de ampliação de vagas para o ensino superior tenham como objetivo a democratização do sistema de ensino, na conjuntura atual, observam-se sinais de desigualdades sociais que acabam por conduzir os indivíduos que emergem do meio social mais desfavorecido para cursos de baixo prestígio e aqueles oriundos de estratos superiores para cursos de maior reconhecimento social.

De acordo com Paula e Silva, o foco da política de expansão e de massificação não se reduz à democratização da educação superior. Para elas, "Esse processo só se completará se tivermos igual proporção de crescimento na taxa de concluintes, com integração crescente das camadas marginalizadas socialmente, sobretudo dos estudantes de baixa renda" (2012, p. 7).

A crescente expansão do ensino superior reforça a necessidade da reformulação de ações para que também seja garantida a permanência desses estudantes na universidade pública. Vale lembrar que essa inclusão tem efetivado a entrada de alunos com perfis sociais diversificados, o que demanda investimentos no âmbito da Assistência Estudantil para que milhares de jovens da classe baixa e oriundos de escolas públicas tenham a possibilidade não só de ingressar, mas também de permanecer na universidade. Afinal, pelo que observamos no presente estudo, as condições materiais podem vir a justificar a causa do grande número de evasão e de retenção no ensino superior.

As políticas institucionais e governamentais apresentadas neste artigo têm buscado promover a democratização do ensino, fazendo com que uma nova população, oriunda das classes populares, tenha condições de ingressar na universidade. Lembramos que esse perfil a que nos referimos, além de ser de origem economicamente desfavorecida, tem trajetórias de escolarização em 


\section{movimento \\ faculdade de educação - programa de pós-graduação em educação \\ universidade federal fluminense \\ issn 2359-3296 \\ ano 5 número 9 - 2018}

escolas públicas e são os autodeclarados afrodescendentes, indígenas ou portadores de necessidades especiais.

No entanto, essa ampliação de oportunidades de acesso e a criação de vagas constituem apenas uma das faces do processo de democratização. Entende-se que, para que essas ações sejam verdadeiramente efetivas, é necessária a implantação de medidas mais intensas que promovam também a permanência desses jovens durante toda a realização do curso.

Com o impedimento da presidenta Dilma e com o início do governo ilegítimo do agora presidente Michel Temer em 31 de agosto de 2016, as instituições federais de ensino superior sofreram ataques e descontinuidades das propostas anteriores, com influências significativas em sua estrutura, configurando um retrocesso nos recentes avanços. Logo no início de seu governo o presidente aprovou a proposta de Emenda à Constituição de número 55, em 13 de dezembro de 2016, denominada como PEC do Teto dos Gastos Públicos, a qual prevê o congelamento dos gastos na saúde e na educação em um período de 20 anos.

Essa emenda prevê a redução dos gastos a partir de 2018. No entanto, já em 2017, passávamos por expressivos cortes nas universidades públicas, o que influenciou diretamente em seu funcionamento. Entre janeiro e junho desse ano, quase $70 \%$ nas universidades tiveram cortes. A UFRJ, por exemplo, funcionou com $22 \%$ a menos de seu orçamento ${ }^{10}$. O corte influenciou diretamente na rotina da instituição, inclusive comprometendo o pagamento de bolsas ${ }^{11}$ para os graduandos. Para 2018, o governo prevê a administração de

\footnotetext{
10 Informações disponíveis em: https://g1.globo.com/educacao/noticia/quase-70-dasuniversidades-federais-do-pais-tiveram-cortes-no-orcamento-entre-janeiro-e-junho.ghtml

${ }_{11}$ A UFRJ, através de incentivos do PNAES, destina bolsas (no valor de $\mathrm{R} \$ 460,00$ acrescidos de $R \$ 150,00$ para transporte) para estudantes egressos do ensino médio público com renda per capita de até 1,5 salários mínimos.
} 


\section{movimento \\ faculdade de educação - programa de pós-graduação em educação \\ universidade federal fluminense \\ issn 2359-3296 \\ ano 5 número 9 - 2018}

$50 \%$ da verba das universidades públicas federais que até então administravam $100 \%$ de seu orçamento.

Baseado na ideia neoliberal de uma educação mercadológica, o governo federal solicitou ao Banco Mundial o relatório ${ }^{12}$ : "Um ajuste justo: análise da eficiência e equidade do gasto público no Brasil", com a finalidade de realizar uma análise sobre o gasto público no Brasil e de identificar alternativas para a redução do déficit fiscal. Em suma, o documento concluiu que o ensino superior público brasileiro, comparado ao privado, é ineficiente e, por isso mesmo, deveria ser pago. Sem levar em consideração, por exemplo, a realidade do país frente às desigualdades de acesso e de permanência na universidade por estudantes das camadas populares.

Por fim, a perda de verbas públicas na educação, mais precisamente no contexto da UFRJ, atinge diretamente a vida dos estudantes e representa uma descontinuidade das efetivas políticas públicas de acesso e de permanência. Afinal, como uma vitória no campo da democracia, tais ações trouxeram como resultado o aumento de ingressantes por políticas de reservas de vagas e a criação de projeto e programas de assistência estudantil.

\section{Referências}

ASSOCIAÇÃO DOS DOCENTES DA UFRJ (AsDUFRJ). Estudantes protestam contra atraso na reforma do alojamento. Rio de Janeiro, 2016a. Disponível em: https://adufri.org.br/noticia/estudantes-protestam-contra-atraso-na-reforma-doalojamento/ Acesso em: 05.maio.2018.

\footnotetext{
${ }^{12}$ Para mais informações:

http://documents.worldbank.org/curated/en/884871511196609355/pdf/121480-REVISED

PORTUGUESE-Brazil-Public-Expenditure-Review-Overview-Portuguese-Final-revised.pdf
} 


\section{moviminto \\ faculdade de educação - programa de pós-graduação em educação \\ universidade federal fluminense \\ issn 2359-3296 \\ ano 5 número 9 - 2018}

Reitoria distribui quentinhas. Rio de Janeiro, 2016b. Disponível em:

$<$ https://adufrj.org.br/noticia/reitoria-distribui-quentinhas/> Acesso em:

05.maio.2018.

BRASIL. Presidência da República. Lei n. 5.540, de 28 de novembro de 1968.

Fixa normas de organização e funcionamento do ensino superior e sua articulação com a escola média, e dá outras providências. Brasília, 1968.

. Presidência da República. Lei n. 10.260, de 12 de julho de 2001. Dispõe sobre o Fundo de Financiamento ao estudante do Ensino Superior e dá outras providências. Brasília, 2001.

. Presidência da República. Lei n. 11096, de 13 de janeiro de 2005. Institui o Programa Universidade para Todos - PROUNI, regula a atuação de entidades beneficentes de assistência social no ensino superior; altera a Lei no 10.891, de 9 de julho de 2004, e dá outras providências. Brasília, 2005.

. Presidência da República. Lei n. 12.711, de 29 de agosto de 2012. Dispõe sobre o ingresso nas universidades federais e nas instituições federais de ensino técnico de nível médio e dá outras providências. Brasília, 2012.

COMIN, Álvaro A.; BARBOSA, Rogério J. Trabalhar para estudar: a pertinência da noção de transição-escola no Brasil. Novos Estudos CEBRAP, São Paulo, n. 91, p. 75-95, nov. 2011.

FÁVERO, Maria de Lourdes de Albuquerque. A Universidade no Brasil: das origens à Reforma Universitária de 1968. Educar; Curitiba, n.28, p. 17-36. Editora UFPR. 2006.

FLACSO. Lei 12.711/2012: novos desafios. Cadernos do Pensamento Crítico Latino-Americano, 2012.

HERINGER, Rosana; HONORATO, Gabriela. Políticas de permanência e assistência no ensino superior público e o caso da Universidade Federal do Rio de Janeiro (UERJ). In: BARBOSA, Maria Ligia de Oliveira [org.]. Ensino Superior: expansão e democratização. Rio de Janeiro, RJ: 7Letras, 2014. p. 315-350.

HONORATO, Gabriela. Investigando a "permanência" no ensino superior: um estudo sobre cotistas do curso de pedagogia da UFRJ. In: HONORATO, Gabriela; HERINGER, Rosana. Acesso e sucesso no ensino superior: uma sociologia dos estudantes. 1aㅡ ed. Rio de Janeiro, RJ: 7Letras: FAPERJ, 2015. p. 96-132. 


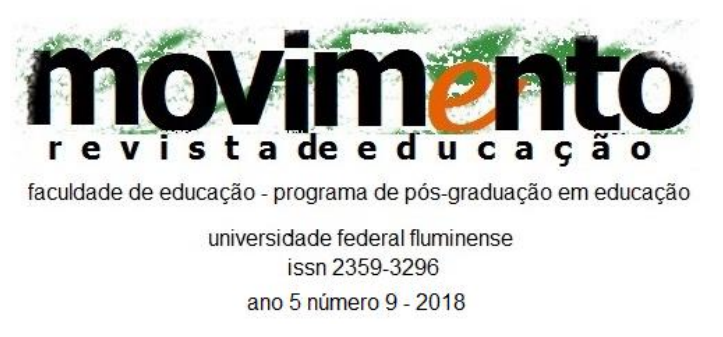

. Introdução. In: HONORATO, Gabriela; HERINGER, Rosana. Acesso e sucesso no ensino superior: uma sociologia dos estudantes. $1^{\text {a }}$ ed. Rio de Janeiro, RJ: 7Letras: FAPERJ, 2015. p. 8-31.

INSTITUTO NACIONAL DE ESTUDOS E PESQUISAS EDUCACIONAIS ANÍSIO TEIXEIRA. Sinopse Estatística da Educação Superior 1995 e 2002. Brasília: MEC/INEP, 2002.

2014. . Censo da Educação Superior - Resumos Técnicos 2014. MEC/INEP,

LI, Denise Leyi. O novo Enem e a plataforma Sisu: efeitos sobre a migração e a evasão estudantil. Dissertação para a obtenção do título de Mestre em Ciências na Universidade de São Paulo. 108p. São Paulo, 2016. Disponível em: <http://www.teses.usp.br/teses/disponiveis/12/12138/tde-23112016094256/pt-br.php>. Acesso em: 04.maio.2018.

MAGALHÃES. Rosélia Pinheiro de. Assistência Estudantil e o seu papel na Permanência dos Estudantes de Graduação: A Experiência da Universidade Federal do Rio de Janeiro. Dissertação de Mestrado. Rio de Janeiro: PUC, 2013.

. SILVA, M.G.M. (Org.). As políticas de democratização da educação superior nos estados do Rio de Janeiro e de Mato Grosso: produção de pesquisas e questões para o debate. Cuiabá: EDUFMT, 2012.

PNE. Observatório do PNE. Educação Superior.

Disponível em: < http://www.observatoriodopne.org.br/metas-pne/12-ensinosuperior> Acesso em: 09.06.2018.

PORTES, Écio Antônio. E agora José? In: HONORATO, Gabriela; HERINGER, Rosana. Acesso e sucesso no ensino superior: uma sociologia dos estudantes. 1를. Rio de Janeiro, RJ: 7Letras: FAPERJ, 2015. p. 135-141.

SUPEREST. Programa de Bolsas e Benefícios ao Estudante, 2016. Disponível em: < http://politicasestudantis.ufrj.br/index.php/programa-de-bolsas>. Acesso em: 06. maio.2018.

UNIVERSIDADE FEDERAL DO RIO DE JANEIRO (UFRJ). Resolução CEG 01/2008 normas de concessão e renovação de auxílio ao estudante, 2008. Disponível em: http://superest.ufrj.br/images/resoluo_ceg_01-2008.pdf Acesso em: 04. fev. 2018. 


\section{movimento \\ faculdade de educação - programa de pós-graduação em educação \\ universidade federal fluminense issn 2359-3296 \\ ano 5 número 9 - 2018}

. Edital no225 de 25 de outubro de 2012 (Normas Complementares ao Edital 223 de 25 de outubro de 2012) Acesso aos Cursos de Graduação com vagas a serem ocupadas pelo Sistema de Seleção Unificada do MEC - SiSU/MEC. Rio de Janeiro, 2012. Disponível em: $<$ http://acessograduacao.ufri.br/images/ Acesso-2013/2013-Editais/2013 Edital\%20No\%20225\%20-\%20Acesso\%20SiSU.pdf>. Acesso em: 05.maio.2018.

. UFRJ em números. Rio de Janeiro, 2013. Disponível em: $<$ https://ufri.br/docs/lai/ufri-em-numeros-2013.pdf> Acesso em: 04.maio.2018 VARGAS, Hustana Maria. Repensando e distribuindo a distinção: a barragem do ensino superior. 2008. 232 f. Tese (Doutorado em Educação) - Pontifícia Universidade Católica do Rio de Janeiro, 2008.

\section{SOBRE AS AURORAS}

JOYCE SOARES PESSANHA. é Mestranda em Educação pela Universidade Federal Fluminense (UFF). Professora da Rede Pública e Privada do Estado do Rio de Janeiro.

E-mail: ioyce 524@hotmail.com

AMANDA GONÇALVES DA SILVA é Doutoranda em Educação pela Universidade Federal Fluminense.

E-mail: amandags@id.uff.br

MARIANE BRITO DA COSTA é Doutoranda em Educação pela Universidade Federal Fluminense (UFF). Professora e orientadora educacional da rede municipal e estadual da cidade do Rio de Janeiro. E-mail:marianecosta0428@gmail.com 